\title{
Topic Study Group No. 3: Mathematics Education in and for Work
}

\author{
Geoff Wake, Diana Coben, Burkhard Alpers, Keith Weeks \\ and Peter Frejd
}

At ICME-13 TSG 3 aimed to bring together researchers, practitioners and policy makers for the exchange of ideas related to Mathematics education in and for work. Our wish was to be inclusive in our endeavours by involving those interested in this area from mathematics education, adult education, workplace education, adult numeracy education, citizenship education, social movement education and other fields.

In pursuit of our work we considered mathematics to be inclusive of the formal academic discipline of mathematics and mathematical processes such as modelling and problem solving in addition to many other informal forms of quantitative reasoning that arise in a wide range of work settings and situations.

We took education to be inclusive of formal, informal and non-formal learning, that is, in educational settings (e.g. adult community education, vocational and further education) as well as in the community and workplaces; and to involve both individual and collective learning.

We also took a view of work to be inclusive of both paid and unpaid work such as work in the home, and activist work in social movements. We recognised that work has very different meanings in the full range of different social and cultural settings and in many cases is evolving rapidly.

Co-chairs: Geoff Wake, Diana Coben.

Team members: Burkhard Alpers, Keith Weeks, Peter Frejd.

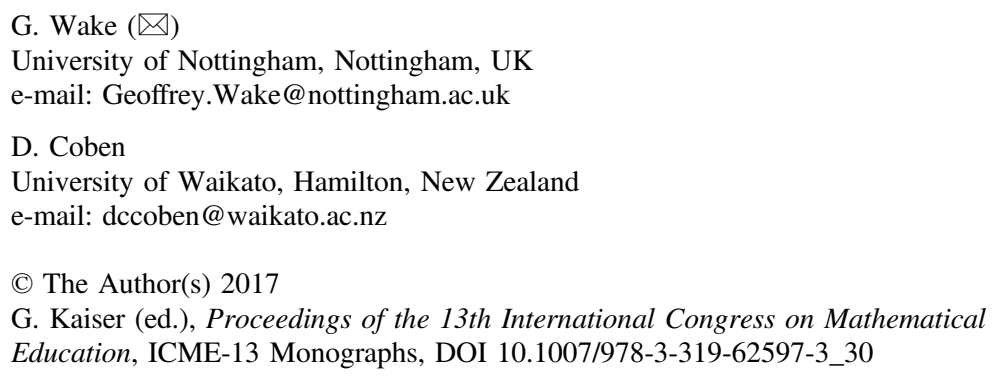


The focal topics of the group included empirical, theoretical and methodological issues related to questions such as:

- How is mathematics embedded in work practices; what is this mathematics like and how is it learned?

- How can we define and model competence in work-based mathematics? How can we use diagnostic assessment to understand such competence?

- What mathematics do people currently learn in preparation for work? How could/should this be improved?

- How is mathematics/numeracy valued for and in employment in different societies?

- How does the mathematics learning in and for work meet people's mathematical needs in other domains of their lives?

We planned for and provided a lively forum for debate that involved different modes of exchange, including presentations, posters and discussions and were informed by contributions from a range of different theoretical perspectives and research backgrounds.

On Tuesday we focussed on the Question: What makes for authenticity in mathematics education in and for work?

The following contributions answered this question. Diana Coben \& Keith Weeks with the title: "Authenticity in vocational mathematics: Supporting medication dosage calculation problem solving in nursing"; Vincent Jonker, Monica Wijers, Ad Mooldijk, Mieke Abels \& Michiel Doorman: "Redesign guidelines to enrich classroom tasks for maths and science"; Kees Hoogland \& Birgit Pepin: "The numeracy of vocational students: Exploring the nature of the mathematics used in daily life and work".

The session on Wednesday was chaired by Keith Weeks and focussed on the question: "How do we make sense of mathematics in and for work using different research methodologies and theoretical approaches?" The following contributions were made:

- John Keogh \& Theresa Maguire: "Re-contextualising mathematics for the workplace"; Lisa Björklund Boistrop: "Mathematics in the workplace from different perspectives: The case of Anita, a Nursing Aide"; David Pontin: "Vocational mathematics and nursing: Social messiness and complexity".

- "What is the role and place of mathematics in education in and for work?" was the question posed on Friday by Peter Frejd and this was answered by the following presentations by two scholars:

- Phil Kane: "Uncovering estimation and spatial awareness as elements of workplace numeracy" and Karen Reitz-Koncebovski \& Katja Maaß: "Dialogue between school and the world of work in teacher professional development (PD)". 
On Saturday the question posed by Geoff Wake was "What is the role and place of mathematics in education in and for work?" Nathalie Jennifer van der Wal, Arthur Bakker \& Paul Drijvers answered the question with their presentation titled "Techno-mathematical literacies in the workplaces of engineers" and the debate was taken further by Damon Whitten who presented: "Inside a mathematicsfor-work lesson on ratio".

Open Access Except where otherwise noted, this chapter is licensed under a Creative Commons Attribution 4.0 International License. To view a copy of this license, visit http://creativecommons. org/licenses/by/4.0/.

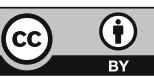

